\title{
The Impact of Hyperthyroidism on Selected Serum Proteins and Metal Ions in the Population of Lahore and its Surrounding Areas
}

\author{
Aisha Munawar ${ }^{* 1}$, Zahid Ali ${ }^{1,2}$, Farzana Muneib ${ }^{3}$, Abu Baker Shahid ${ }^{3}$, \\ Ahmed Akrem ${ }^{4}$ and Syed Abid $\mathrm{Ali}^{5}$ \\ ${ }^{1}$ Department of Chemistry, University of Engineering and Technology, Lahore, Punjab, Pakistan. \\ ${ }^{2}$ Department of Chemistry, The University of Lahore, Lahore, Pakistan. \\ ${ }^{3}$ Radio Immuno Assay lab, INMOL Hospital, Lahore, Punjab, Pakistan. \\ ${ }^{4}$ Botany Division, Institute of Pure and Applied Biology, Bahauddin Zakariya University, Multan, Pakistan. \\ ${ }^{5}$ H.E.J. Research Institute of Chemistry, International Center for Chemical and Biological Sciences (ICCBS), \\ University of Karachi, Karachi, Pakistan. \\ *Corresponding Author Email: aisha.munawar@uet.edu.pk \\ Received 13 March 2019, Revised 15 October 2019, Accepted 20 October 2019
}

\begin{abstract}
Inorganic metal ions and the proteins play an essential role in living systems. Different hormones and cellular messengers regulate the hemostasis of organisms. Calcium, magnesium, iron and zinc are abundantly distributed in human bodies and play vital role in many biochemical processes. Albumin and ferritin are also the most abundant proteins present in our bodies and carrying out important physiological processes. A disease state or a medical condition can perturb the normal levels of metal ions and proteins in living systems. In the present study, we have analyzed the serum concentration of $\mathrm{Ca}, \mathrm{Mg}, \mathrm{Fe}, \mathrm{Zn}$, albumin and ferritin of hyperthyroid patients. This study includes 184 collected samples (52 normal subjects and 132 hyperthyroid patients), with age group ranging between 11 to 75 years. During sample collection, only those patients were included for whom hyperthyroidism was initially diagnosed but not taking any medicines yet. The hyperthyroid state was determined by the correlation of $\mathrm{FT}_{3}, \mathrm{FT}_{4}$ and TSH. Serum Fe, Ca and albumin levels were determined by spectrophotometric method, while $\mathrm{Zu}$ and $\mathrm{Mg}$ by atomic absorption spectroscopy (AAS) and ferritin by radioimmunology assay (RIA). Obtained results demonstrated the significant differences in the studied parameters as compared to the normal subjects.
\end{abstract}

Keywords: Ferritin, Albumin, Hyperthyroidism, Zinc, Iron, Calcium, Magnesium, TSH

\section{Introduction}

Thyroid disease is one of the most common endocrine disorder. Studies have shown that about 108 million people in India are distressed from metabolic and endocrine syndrome, of which approximately 42 million are thyroid aberrations [1]. Hyperthyroidism is chiefly due to overexcited activity of thyroid gland and some other roots [2]. Many physiological, clinical and biochemical changes occur when body tissues are exposed for long time to higher concentrations of thyroid hormone [3, 4]. The hemostasis the body is an intricate process, involving different hormones, proteins and metal ions etc. In this connection albumin and ferritin are important proteins present in the blood. Both of these belong to the family of globular protein [5]. Ferritin is responsible for the storage of iron, while albumin is a transportation protein. Albumin transports metal ions and different hormones in the body, and is responsible for carrying zinc and thyroid hormones [6, 7]. 
Crystallographic studies revealed that albumin consists of a heart shaped assembly of three homologous domains, while the ligand binding domain is located in the hydrophobic cavities present between two subdomain IIA and IIIA [5, 8], and the zinc binding site is present at the interface of domains I and II [7]. Zinc is of great importance too as it is the most common metal ion present at the active site of metalloproteinase, which are involved in many biochemical processes, e.g. angiotensin converting enzyme, which is an important enzyme in the blood pressure regulation [9]. The normal concentration of zinc in blood serum is required for the proper functioning of pituitary gland, hypothalamus and for the biosynthesis of Thyrotropin Releasing Hormone (TRH) in the human body $[10,11]$. It also plays a key role in the deiodination of thyroxine T4 [12]. The alteration of zinc level is well reported in hyperthyroidism and thyroid cancer [13, 14], and mainly observed in erythrocytes and brain tissues [15].

Iron plays an important role in transport of oxygen throughout the body by binding with hemoglobin. Magnesium is a cofactor for about 300 cellular enzymes and has an imperative role in energy metabolic rate, contributing in phosphatetransfer reactions concerning ATP and nucleotide triphosphates for efficient integrity of the nervous system [16]. Several research reports have shown that a decrease in the amount of serum magnesium is related to increased inflammation [17]. Through a large number of studies, it has been well established that calcium is mainly responsible for the bone health and also prevents bone loss [18]. Hyperthyroidism affects the bone mineral homeostasis and diminution the bone density [19]. Primarily bone mineral homeostasis is controlled by the following three major hormones including calcitonin, parathyroid hormone (PTH) and 1,25dihydroxyvitamin D [20]. Moreover, thyroid hormones mainly target intestine, bone, kidney and heart tissues, and may indirectly influence the hemostasis [21].

In the light of aforementioned important role of different proteins and metal ions in the human physiology, and a possibility of disturbance/imbalance in their serum level, we have designed a systematic study to find out if there is any affect of hyperthyroidism on iron, zinc, calcium, magnesium, albumin and ferritin. Another aim of this study was to see if geographical location and race has any correlation with the factors studied.

\section{Materials and Methods Subjects}

A clinical based descriptive study was conducted during the period from February to June 2017. This study encompassed over 184 samples having 52 healthy persons (age ranging between 11 to 67 years, and 132 (109 males and 33 females) hyperthyroid patients, with age ranging between 11 to 72 years. More than 1000, patients were attended and test group was selected on the basis, in all the patients, hyperthyroidism was initially diagnosed. None of them had any major disease, like hepatitis, thalassemia, anemia/sickle cell anemia, and had not gone under any major or minor surgery, in the past 18 months. The patients were attended and interviewed at radioimmunoassay laboratory (RIA), INMOL Hospital Lahore. The patients were spotted on the result of clinical examination and by the correlation of $\mathrm{FT}_{3}, \mathrm{FT}_{4}$ and $\mathrm{TSH}$. Written consent was obtained from each patient to use his or her blood samples for this study. The purpose and nature of the research work was fully explained to them, before collecting their blood sample. Concentration of calcium and albumin was determined using Erba Kit (ERBA diagnostic Mannheim GmbH, Germany). Iron was also determined by, Iron Assay Kit (Elabscience, USA). Ferritin-IRMA Kit was used for the determination of serum ferritin. Thyroid hormone concentration was determined by using Beckman Coulter Kit. All other chemicals used were obtained from Merck (Germany), unless otherwise stated.

\section{Control Group}

The control group consisted of 52 blood samples, obtained from healthy persons.

\section{Test/Case Group}

The test group consisted of 132 blood samples, obtained from hyperthyroid patients. 


\section{Sample Collection and Preparation}

Approximately $5 \mathrm{~mL}$ venous blood was drawn from each person by employing disposable syringe and then transported into coated tubes (coated with antibodies labelled with $\mathrm{I}^{125}$ ) for clotting. The serum was separated from the plasma by centrifugation at $3000 \mathrm{rpm}$ for ten min. Serum samples were stored at $-20^{\circ} \mathrm{C}$ temperature before use.

\section{Determination of FT3, FT4 and TSH}

Serum hormone levels of $\mathrm{FT}_{4}, \mathrm{FT}_{3}$ and TSH were estimated by using RIA/IRMA methodology using kits manufactured by Beckman coulter on Gamma Counter SR 300 [22-24].

\section{Determination of Zinc and Magnesium}

The serum samples were digested as follows. $2 \mathrm{~mL}$ of nitric acid (65\%, analytical grade) were added to $0.5 \mathrm{~mL}$ of serum, followed by addition of $1 \mathrm{~mL}$ of $30 \% \mathrm{H}_{2} \mathrm{O}_{2}$. The mixture was heated in a beaker till the evaporation of acid. The residue was dissolved in $25 \mathrm{~mL}$ water and stored at $4^{\circ} \mathrm{C}$, till analysis by atomic absorption spectrophotometer (AAS). Stock solution of zinc was prepared by dissolving $1 \mathrm{~g}$ of zinc metal granules (99.9\%; Fisher scientific, USA) in 1:1 mole ratio of $40 \mathrm{~mL}$ hydrochloric acid and distilled water then diluted up to $1 \mathrm{~L}$ to obtain $1000 \mu \mathrm{g} / \mathrm{mL}$ of zinc. Working standards of 100, 10, 5, 2 and 1 ppm were prepared by diluting the stock solution with distilled water. Likewise, stock solution of magnesium was prepared by using anhydrous magnesium chloride. In order to determine the absorbance of digested samples for magnesium, zinc by atomic absorption spectrophotometer (Varian 240, Co. USA), and auto-sampler was used for aspiration of the samples. Acetylene flame at $0.1 \mathrm{~nm}$ flame width and $213.9 \mathrm{~nm}$ wavelength was used for the analysis. The $\mathrm{Mg}$ and $\mathrm{Zn}$ concentration of each sample was calculated using standard curve

[25].

\section{Estimation of Iron, Calcium and Albumin}

The concentration of serum albumin, iron and calcium was determined by using assay kits based on colorimetric method, with Micro-lab-200, spectrophotometer. The protocols provided by the supplier with the assay kits were followed ideally.

\section{Estimation of Serum Ferritin Levels}

Serum ferritin levels were determined by RIA/ IRMA methodology, by using Gamma Counter SR 300, (Co. USA). The procedure provided by the manufacturer of the ferritin assay kit was followed exactly.

\section{Statistical Analysis}

All the statistical evaluations were made using Excel software.

\section{Results and Discussion}

The obtained results of our study show that mean serum $\mathrm{FT}_{4}, \mathrm{FT}_{3}$, have increased significantly $(p<0.001)$ in hyperthyroid patients as compared to normal subjects, while mean serum TSH has declined significantly (Fig. 1). All the other parameters tested were found in the normal range, although subtle differences in the level of these parameters were observed when compared to the control group, as data summarized in Table 1. The concentration of TSH was very low in hyperthyroid cases, which enriches the serum with $\mathrm{FT}_{3}$ and $\mathrm{FT}_{4}$ in prominent way, because of malfunction of thyroid gland (Fig. 1).

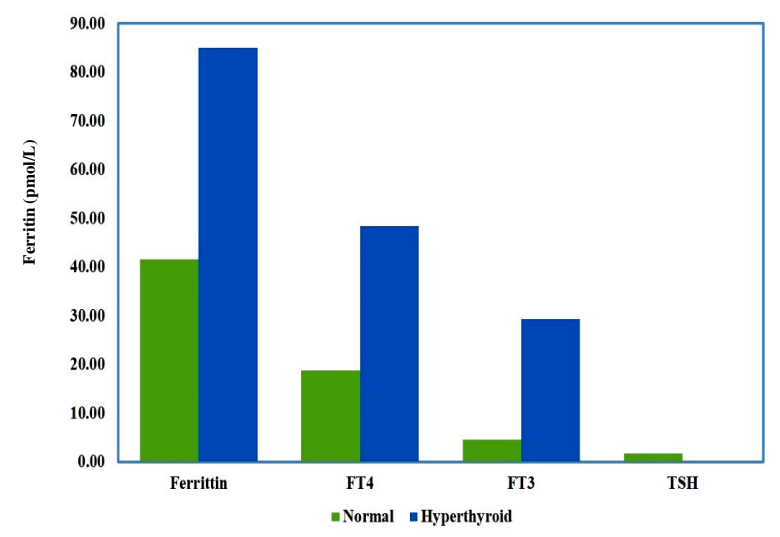

Figure 1. Comparison in the mean thyroid related hormone and ferritin in both groups

Hyperthyroidism generally increases the storage of serum iron and decrease the iron metabolism in all age groups and genders, 
particularly in menopausal and premenopausal women in accordance with clinical endocrinology recommendations. There was a significant increase observed in serum ferritin level of hyperthyroid patients, which is evident from the Fig. 2 and Table 1. Regression analysis was also carried out to study correlation among different parameters studied, and the data obtained were summarized in Table 2. All the plots of regression analysis are shown in Fig. 3.

Table 1. Statistical analysis of the investigated parameters by student's t-test.

\begin{tabular}{lccc}
\hline \multirow{2}{*}{ Analyte } & \multicolumn{2}{c}{ Mean \pm S.D } & Significance \\
\cline { 2 - 3 } & $\begin{array}{c}\text { Control } \\
\text { Group }\end{array}$ & $\begin{array}{c}\text { Hyperthyroid } \\
\text { Group }\end{array}$ & $\begin{array}{l}\text { level } \\
\mathrm{FT}_{4} \mathrm{p} \mathrm{mol} / \mathrm{L}\end{array}$ \\
$13.41 \pm 5.34$ & $31.44 \pm 17.0$ & $\mathrm{P}<0.001$ \\
$\mathrm{FT}_{3} \mathrm{p} \mathrm{mol} / \mathrm{L}$ & $4.33 \pm 0.31$ & $21.61 \pm 7.71$ & $\mathrm{P}<0.001$ \\
TSH ml U/L & $1.43 \pm 0.23$ & $0.075 \pm 0.015$ & $\mathrm{P}<0.001$ \\
Ferritin ng/mL & $51.48 \pm 8.03$ & $85.61 \pm 8.12$ & $\mathrm{P}<0.001$ \\
Albumin g/dL & $4.4 \pm 0.29$ & $3.0 \pm 0.59$ & $\mathrm{P}<0.001$ \\
Iron $\mu \mathrm{g} / \mathrm{dL}$ & $89.63 \pm 5.6$ & $80.00 \pm 10$ & $\mathrm{P}<0.05$ \\
Zinc ng/dL & $244 \pm 13.8$ & $172.5 \pm 10.6$ & $\mathrm{P}<0.05$ \\
Ca mg/dL & $8.3 \pm 0.30$ & $9.2 \pm 0.24$ & $\mathrm{P}<0.001$ \\
Mg mg/dL & $5.2 \pm 0.5$ & $3.5 \pm 0.48$ & $\mathrm{P}<0.001$ \\
\hline
\end{tabular}

Table 2. Regression analysis between the different investigated parameters.

\begin{tabular}{lccc}
\hline \multicolumn{1}{c}{ Analyte } & $\begin{array}{c}\text { Regression } \\
\text { factor }(\mathbf{r})\end{array}$ & $\mathbf{Y}=\mathbf{a}+\mathbf{b x}$ & $\begin{array}{c}\text { Significance } \\
\text { level } \boldsymbol{t} \text {-test }\end{array}$ \\
\hline TSH vs ferritin & 0.19 & $\mathrm{Y}=79.2-14.7 \mathrm{x}$ & 0.001 \\
FT3 vs ferritin & 0.23 & $\mathrm{Y}=45.2+1.21 \mathrm{x}$ & 0.001 \\
FT4 vs ferritin & 0.32 & $\mathrm{Y}=19.7+1.32 \mathrm{x}$ & 0.001 \\
FT4 vs Iron & 0.21 & $\mathrm{Y}=54.8+6.9 \mathrm{x}$ & 0.05 \\
Iron vs ferritin & 0.15 & $\mathrm{Y}=83.2+0.07 \mathrm{x}$ & 0.5 \\
FT4 vs Zinc & -0.22 & $\mathrm{Y}=250-1.42 \mathrm{x}$ & 0.01 \\
FT3 vs Zinc & -016 & $\mathrm{Y}=220-1.17 \mathrm{x}$ & 0.5 \\
TSH vs Zinc & 0.25 & $\mathrm{Y}=177+29.9 \mathrm{x}$ & 0.01 \\
FT4 vs albumin & -0.48 & $\mathrm{Y}=4.2-0.014 \mathrm{x}$ & 0.001 \\
Albumin vs zinc & 0.29 & $\mathrm{Y}=30.6+4.73 \mathrm{x}$ & 0.001 \\
FT 4 vs Ca & 0.04 & $\mathrm{Y}=17.9+0.005 \mathrm{x}$ & 0.001 \\
TSH vs Ca & -0.02 & $\mathrm{Y}=9.19-0.04 \mathrm{x}$ & 0.001 \\
FT 4 vs Mg & -0.52 & $\mathrm{Y}=10.9-0.03 \times$ & 0.001 \\
TSH vs Mg & 0.54 & $\mathrm{Y}=3.79+0.58 \mathrm{x}$ & 0.001 \\
\hline
\end{tabular}

There was highly significant negative correlation $(p<0.001)$ established with $\mathrm{r}=0.19$ between serum ferritin concentration and thyroid stimulating hormone TSH. Decreasing concentration of TSH will increase the concentration of ferritin in hyperthyroid patients (Fig. 3a). On the other hand, a highly significant ( $p$ $<0.001)$ positive correlation with $\mathrm{r}=0.23$ was observed between $\mathrm{FT}_{3}$ concentration and ferritin levels. There was a linear relationship observed with a positive slope. Table 1 summarizes the values of iron in both groups. A rectilinear positive association $(p<0.001)$ uphold between the $\mathrm{FT}_{4}$ and ferritin in test groups convincingly evident from the Fig. 3b. Thyroid dysfunction affects the serum iron levels in hyperthyroid patients to a great extent. As a result, serum iron levels in hyperthyroid patients depletes significantly. However, our results do not show much difference in the values between the two groups. There is a negative correlation between serum iron levels and FT4 in blood sera of hyperthyroid patients, which is evident from the Table 2 and Fig. 3c. The relative increase in $\mathrm{FT}_{4}$ concentration will reduce the sera concentration in the hyperthyroid patients. The relative lowering in the serum iron levels also results upsurge in ferritin iron level, which simply can be termed as iron over loading of ferritin. There is a positive undeviating correlation between serum iron concentration and ferritin levels in serum Table 2, Fig. 3d. The shrinkage in the serum ferritin levels results in the very fast hair loss in the patients of all age sets [26]. Iron deficiency results as fetal complications primarily during the course of pregnancy.

There is a linear relationship of $\mathrm{FT}_{4}$ with serum zinc concentration with negative slope, which implies that relative upsurge in these hormones, would result in decreased serum zinc concentration in hyperthyroid patients (Fig. 4a). There is a linear association between TSH and Zinc concentration of hyperthyroid patients with positive regression line which elucidate that a relative lowering of $\mathrm{TSH}$ in hyperthyroidism will decline the serum zinc concentration (Fig. 2c, 4b). 

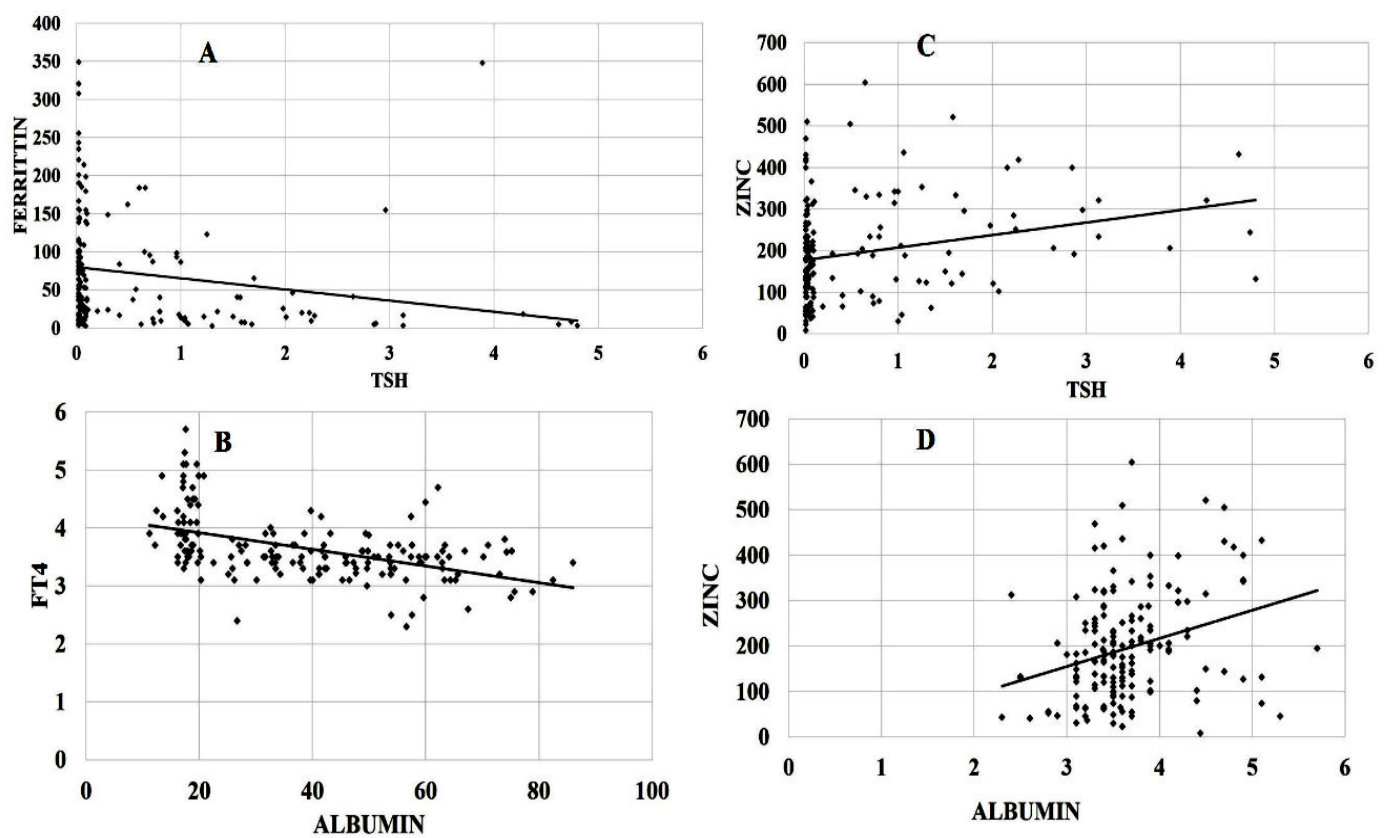

Figure 2. Correlation between the different parameters in hyperthyroid patients (test group). Correlation between ferritin and TSH (A), FT4 and Albumin (B). Zinc and TSH (C) and Zinc and Albumin (D)
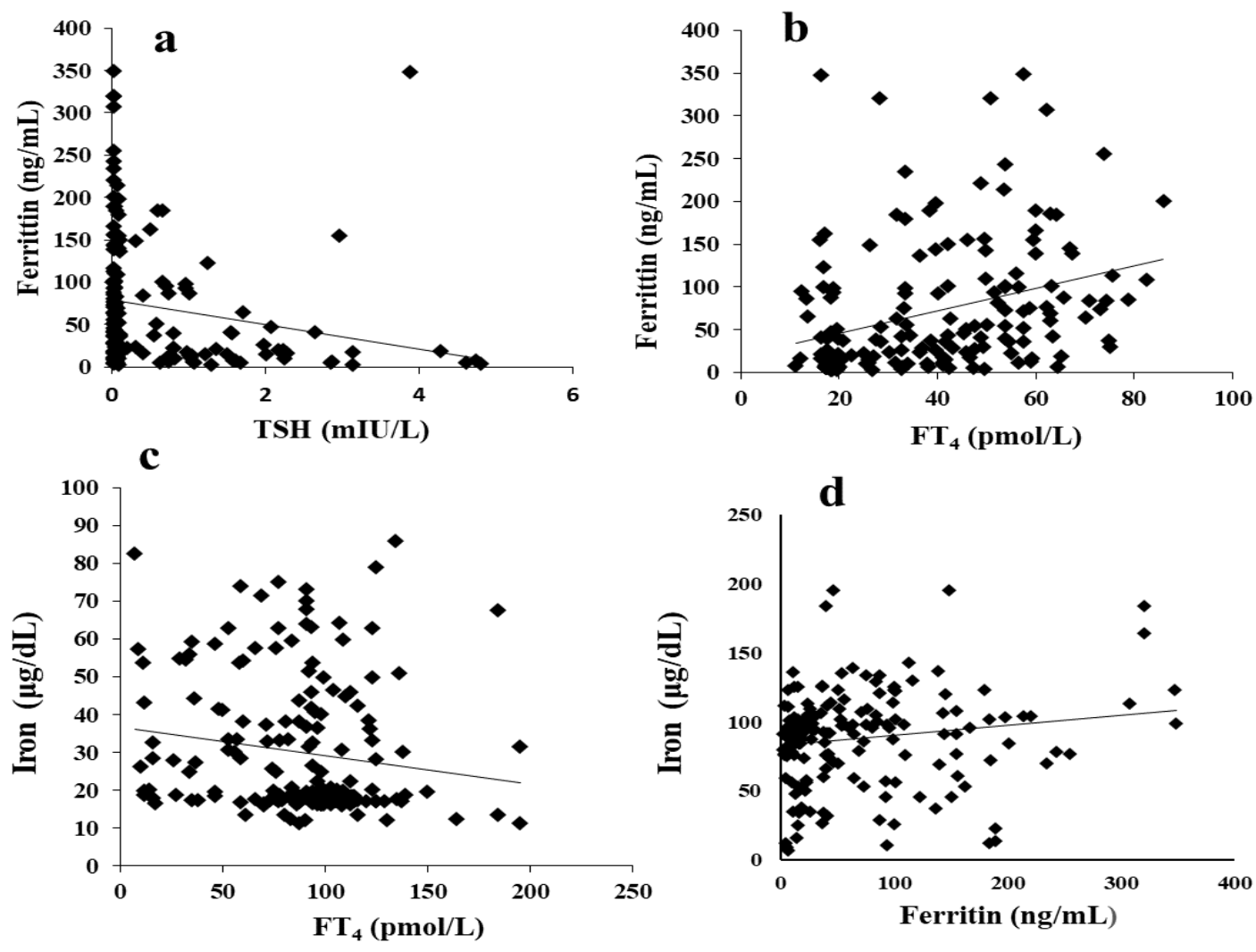

Figure 3. Correlations between thyroid hormones, iron and ferritin, (a) TSH and Ferritin, (b) FT4 and Ferritin, (c) Iron and FT4 and (d) Iron and Ferritin 

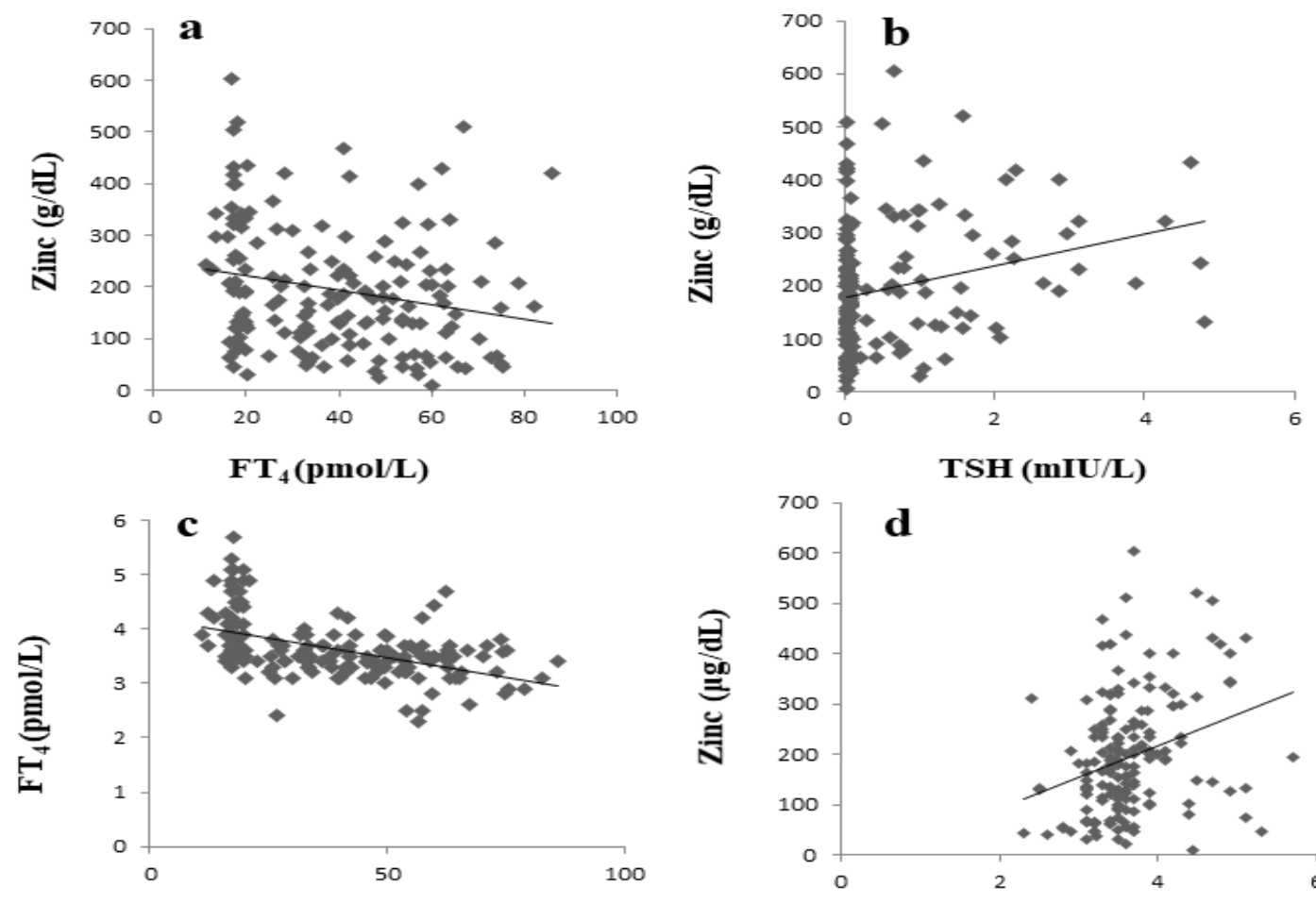

Albumin (g/dL)

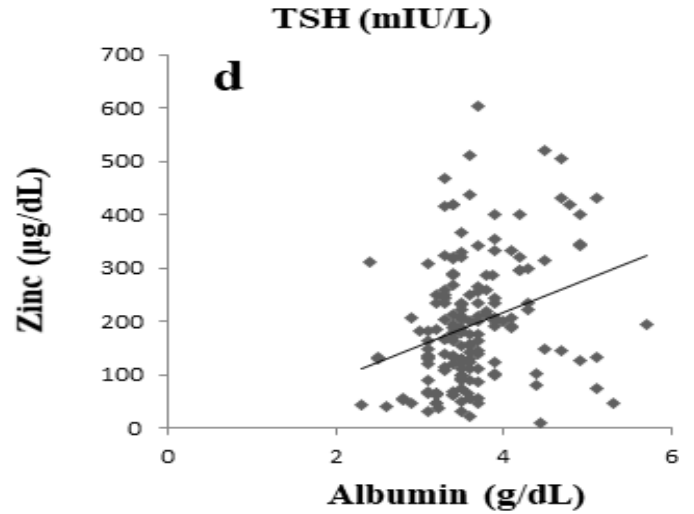

Figure 4. Correlations between TSH, Zn and Thyroid hormones, (a) Zinc and FT4, (b) Zinc and TSH, (c) Albumen and FT4 and (d) Zinc and Albumin
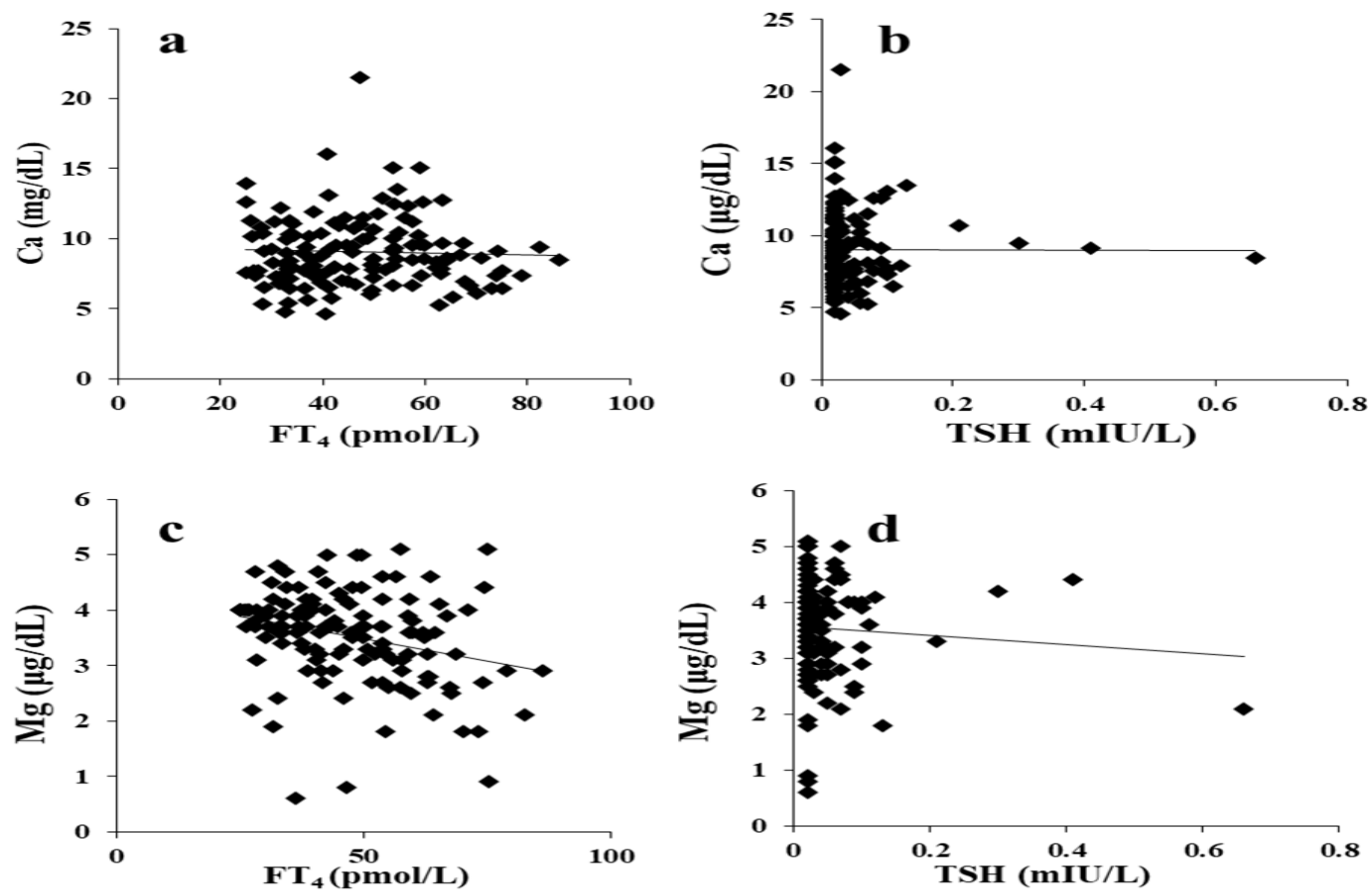

Figure 5. Correlations between Thyroid Harmons, Ca and Mg, (a) FT4 and Ca, (b) TSH and Ca, (c) FT4 and Mg and (d) TSH and Mg 
The amount of albumin analyzed in the hyperthyroid group is lower than the normal range. There is a negative linear correlation between albumin and $\mathrm{FT}_{4}$ for hyperthyroid patients (Fig. 2b), which suggested that a relative increase in the $\mathrm{FT}_{4}$ concentration would decline the concentration of albumin in hyperthyroidism. A positive correlation between zinc and albumin can be seen in Fig. 2d. Calcium is present in relatively higher concentration in hyperthyroid patients as compared to the normal subjects can be visualized from Fig. 5a, 5b. In contrast, there was a negative correlation between $\mathrm{FT}_{4}$ and serum magnesium concentration in hyperthyroidism. Increase in concentration of $\mathrm{FT}_{3}$ in hyperthyroidism will decrease the serum magnesium concentration, which is evident from the data presented in Table 1 and Fig. 5c and 5d. There is a rectilinear correspondence between the sera altitudes of $\mathrm{Ca}$ and $\mathrm{Mg}$ in our findings markedly prescribed in Fig. 5.

Thyroid hormones are responsible for controlling different physiological processes, like cell growth, homeostasis and regulation of metabolism of lipids, carbohydrates, proteins etc. Disturbance in the balance of these hormones can result in various medical problems, like muscle wasting, reduced bone mineral density, insulin release and liver carcinogenesis [27]. In this context we have analyzed, serum levels of calcium, magnesium, zinc, iron, albumin and ferritin. Our study indicates an intricate relationship of these metal ions with the thyroid gland, and shows that it is independent of geographical location and race.

The serum levels of all studied parameters, of the hyperthyroid test group, are present in their normal range except albumin, which is below the normal level. This could be due to the reason that we had selected a group of hyperthyroid patients in whom hyperthyroidism was recently diagnosed (stage of early diagnoses). Thus, it indicates that the disturbance in the balance of these proteins and metal ions, and hemostasis in general might be caused slowly. However, the serum values of the test group in comparison to the normal group (Table 1), show that there are significant differences, following a similar trend reported by several previous studies [26, 27].
Ferritin also possess a buffer action in blood serum, if the rate of iron metabolism is descents, and it will absorb the extra amount of iron to maintain normal levels. In contrast, if the rate of iron metabolism is upturn, ferritin will release more iron to maintain the normal levels [28]. During hyperthyroidism the rate of iron metabolism declines significantly as a result serum ferritin levels surges up, which is also evident from our study. A study carried out on thalassemia patients, concluded that ferritin could be used to predict, the progression to thyroid dysfunction [29]. Previous studies have also shown that increase in the ferritin level of hyperthyroid patients could be the result of direct action of these hormones on the synthesis of ferritin [30].

Serum albumin is responsible for transporting thyroid hormones and zinc ions. A genetic problem known as familial dysalbuminemic hyperthyroxinemia (FDH), due to mutation of the human serum albumin (HSA), results in an increased concentration of serum $\mathrm{T} 4$ [31]. Metabolism of albumin is promoted by thyroid hormones, also hypothyroidism reduces the degradation of albumin [32]. Our results as expected show a significant decline in the level of serum albumin, which is in good agreement with the previous studies [33]. Proliferation in the concentration of thyroid hormones, like FT4 and FT3 will require more quantity of binding proteins, which results in the decline in concentration of pre - albumin and albumin in hyperthyroidism [34]. Our studies also infer that a relative intensification in the thyroid hormones in hyperthyroid case will significantly $(p<0.001)$ decrease the serum albumin concentration. A lowering of serum albumin might disturb the physiological balance, as it is the principle plasma protein, and responsible for the regulation of plasma on tonic pressure and transportation of exogenous and endogenous ligands [5].

In hyperthyroid test group, the concentration of zinc was reduced in blood serum. Previous studies have also reported disturbed level of zinc, in thyroid disorders [35]. There is a significant $(p<0.001)$ linear positive relationship between zinc and albumin according to our current study with $r=0.29$. This relationship suggests that 
a relative reduction in zinc concentration will also lower down the serum albumen concentration. Other studies have also reported a significant correlation between serum zinc and albumin, and a decline in the albumin concentration resulting in the decline of zinc as well [36, 37]. Our study is in line with previous studies and it indicates that zinc is involved in the metabolism of proteins [38].

In the present work, it was also demonstrated that there is substantial diminution of serum magnesium levels in hyperthyroid patients, as also reported previously in literature [39]. Subclinical deficiency of magnesium as a result of chronic disease, leads to cardiovascular infarction and early mortality [40]. Further investigation of the level of calcium in test and control groups revealed significant increase in the level of calcium in the hyperthyroid group. Earlier studies have also reported hypercalcemia in hyperthyroid patients [41]. Increased level of calcium in the serum is also an indication of disturbed calcitonin, a hormone secreted by thyroid gland. The role of calcitonin in the hemostasis of calcium is not clear in human beings, as yet [42]. Our investigation also showed that hyperthyroidism was mainly observed in pre-menopausal and post-menopausal women in the population of Lahore, which is in accordance with a previous study $[43,44]$.

\section{Conclusion}

Hyperthyroidism disturbs the metabolism of calcium, magnesium, iron, zinc, albumin and ferritin. Serum magnesium levels sharply declined in patients with hyperthyroidism, whereas the concentration of calcium significantly surged up. There is also decline in the concentration of both zinc and albumin. The upsurge $\mathrm{FT}_{4}$ and $\mathrm{FT}_{3}$ serum levels also overload the serum iron levels by growing ferritin levels, reducing bioavailability of iron in hyperthyroidism. These changes are highly momentous in pre-menopausal and postmenopausal women. The male population also illustrates this but in diminutive quantity. In male population, this trend is sighted in all age groups not highly specific with any age. Some patients also contain this disorder by birth from their parent. The results of our current work are in accordance with previous studies done in other parts of the world. Therefore, this study clearly shows that, there is no correlation between the disturbance in levels of the serum metal ions, ferritin and albumin with the geographical location and race of the hyperthyroid subjects.

\section{Declaration of interest}

The authors have nothing to disclose and there are no conflicts of interest.

\section{References}

1. N. Kochupillai, Curr. Sci. Bangalore, 79 (2000) 1061.

https://www.jstor.org/stable/pdf/24104359.p df? seq $=1$

2. G. N. Burrow, D. A. Fisher and P. R. Larsen, N. Engl. J. Medi., 331 (1994) 1072. https://doi.org/10.1056/NEJM199410203311 $\underline{608}$

3. M. Ludgate, M. Crisp, C. Lane, S. Costagliola, G. Vassart, A. Weetman, C. Daunerie and M. C. Many, Thyroid, 8 (1998) 411. https://doi.org/10.1089/thy.1998.8.411

4. C. Piras, N. Arisci, S. Poddighe, S. Liggi, S. Mariotti and L. Atzori, Int. J. Biochem. Cell Biol., 93 (2017) 119. https://doi.org/10.1016/j.biocel.2017.07.024

5. C. E. Ha and N. V. Bhagavan, Biochim. Biophys. Acta, 1830 (2013) 5486.

https://doi.org/10.1016/j.bbagen.2013.04.012

6. L. Bartalena and J. Robbins, Clin. Lab. Med., 13 (1993) 583.

https://doi.org/10.1016/S02722712(18)30427-X

7. J. Lu, A. J. Stewart, P. J. Sadler, T. J. Pinheiro and C. A. Blindauer, Biochem. Soc. Trans., 36 (2008) 1317. https://doi.org/10.1042/BST0361317

8. X. M. He, and D. C. Carter, Nature, 358 (1992) 209. https://doi.org/10.1038/358209a0

9. M. Akif, S. L. Schwager, C. S. Anthony, B. Czarny, F. Beau, V. Dive, E. D. Sturrock and K. R. Acharya, Biochem. J., 436 (2011) 53. https://doi.org/10.1042/BJ20102123

10. J. Brandão-Neto, A. C. R. D. Saturnino, L. D. Leite, E. D. de Medeiros Rocha, C. M. P. Marcos, C. A. B. da Silva, J. S. Marchini, A. 
A. de Rezende, M. das Graças Almeida and A. da Cunha Medeiros, Nutr. Res., 26 (2006) 493.

https://doi.org/10.1016/j.nutres.2006.08.010

11. A. E. Pekary, H. C. Lukaski, I. Mena and J. M. Hershman, Peptides, 12 (1991) 1025. https://doi.org/10.1016/01969781(91)90055-T

12. J. King, J. Nutr., 116 (1986) 1045. https://doi.org/10.1093/jn/116.6.1045

13. M. Kucharzewski, J. Braziewicz, U. Majewska and S. Góźdź, Biol. Trace Elem. Res., 93 (2003) 9. https://doi.org/10.1385/BTER:93:1-3:9

14. H. Al-Sayer, T. Mathew, S. Asfar, M. Khourshed, A. Al-Bader, A. Behbehani and H. Dashti, Mol. Cell. Biochem., 260 (2004) 1. https://doi.org/10.1023/B:MCBI.000002602 7.20680.c7

15. N. Liu, Q. Xu, X. Hou, P. Liu, Z. Chai, L. Zhu, Z. Zhao, Z. Wang and Y. Li, Y. Brain Res. Bull., 55 (2001) 309.

https://doi.org/10.1016/S03619230(01)00508-1

16. A. M. P. Romani, A. Sigel, H. Sigel and R. K. O., Editors. Magnesium in Health and Disease, (2013) 49. https://doi.org/10.1007/978-94-007-7500$\underline{8} 3$

17. F. H. Nielsen, J. Inflamm. Res., 11 (2018) 25.

https://doi.org/10.2147/JIR.S136742

18. S. Boonen, R. Rizzoli, P. J. Meunier, M. Stone, G. Nuki, U. Syversen, M. LehtonenVeromaa, P. Lips, O. Johnell and J. Y. Reginster, Osteoporos. Int., 15 (2004) 511. https://doi.org/10.1007/s00198-004-1621-6

19. L. Mosekilde, F. Melsen, J. P. Bagger, O. Myhre-Jensen and N. Schwartz Sorensen, Acta Endocrinol. (Copenh), 85 (1977) 515. https://doi.org/10.1530/acta.0.0850515

20. C. J. Rosen, Primer on the Metabolic Bone Diseases and Disorders of Mineral Metabolism. Ames, Iowa : Wiley-Blackwell. (2013).

https://doi.org/10.1002/9781118453926

21. L. P. B. Elbers, A. Squizzato and V. E. A. Gerdes, Semin. Thromb. Hemost., (2018). doi: $10.1055 / \mathrm{s}-0038-166825$
22. S. Sakata, S. Nakamura and K. Miura, Ann. Intern. Med., 103 (1985) 579. https://doi.org/10.7326/0003-4819-103-4$\underline{579}$

23. E. M. Kaptein, Endocr. Revi., 17 (1996) 45. https://doi.org/10.1210/edrv-17-1-45

24. K. Liewendahl, Scandinavian J. Clin. Lab. Investig., 50 (1990) 83. https://doi.org/10.1080/00365519009085804

25. S. Baloch, A. R. Memon, A. S. Hayat and N. Masood, ARPN J. Sci. Tech., 3 (2011) 3. https://pdfs.semanticscholar.org/1a55/55de9 6e2d0d35f061505987e3ff6aee22507.pdf

26. S. Malkud, J. Clin. Diag. Res., 9 (2015) WC01.

https://doi.org/10.7860/JCDR/2015/14089.6 $\underline{170}$

27. M. A. Kowalik, A. Columbano and A. Perra, Front Endocrinol. (Lausanne), 9 (2018) 382. https://doi.org/10.3389/fendo.2018.00382

28. Y. Kohgo, Int. J. Hematol., 88 (2008) 7. https://doi.org/10.1007/s12185-008-0120-5

29. V. Chirico, A. Lacquaniti, V. Salpietro, N. Luca, V. Ferrau, B. Piraino, L. Rigoli, C. Salpietro and T. Arrigo, Eur. J. Endocrinol., 169 (2013) 785. https://doi.org/10.1530/EJE-13-0627

30. K. Kubota, J. Tamura, H. Kurabayashi, T. Shirakura and I. Kobayashi, Clin. Investig., 72 (1993) 26.

https://doi.org/10.1007/BF00231112

31. S. Refetoff, L. J. Endotext, De Groot, et al., Editors. (2000): South Dartmouth (MA). https://www.ncbi.nlm.nih.gov/books/NBK28 5566/

32. M. K. Kim, H. S. Kwon, K. H. Baek, J. H. Lee, W. C Park, H. S. Sohn, K. W. Lee and K. H. Song, Diabetes Care, 33 (2010) 2546. https://doi.org/10.2337/dc10-0988

33. Nihad Abdul Jabar Jalal, A.H.M. AlSamarrai and K. A. Al-Tikriti, Tikrit J. Pure Sci., 15 (2010).

https://www.iasj.net/iasj?func=fulltext\&aId= 34584

34. M. J. Huang, K. L. Li, J. S. Wei, S. S. Wu, F. D. Fan, Y. F. Liaw, Ame. J. Gastroenterol., 89 (1994).

https://www.ncbi.nlm.nih.gov/pubmed/7912 $\underline{472}$ 
35. E. Przybylik-Mazurek, P. Zagrodzki, S. Kuzniarz-Rymarz and A. HubalewskaDydejczyk, Biol. Trace Elem. Res., 141 (2011) 65.

https://doi.org/10.1007/s12011-010-8719-9

36. E. M. McMillan and D. J. Rowe,. Clin. Exp. Dermatol., 7 (1982) 599.

https://doi.org/10.1111/i.13652230.1982.tb02483.X

37. S. Y. Hess, J. M. Peerson, J. C. King K. H. Brown, Food Nutr. Bull., 28 (2007) S403. https://doi.org/10.1177/15648265070283S303

38. J. Bates and C. J. McClain, Am. J. Clin. Nutr., 34 (1981) 1655.

https://doi.org/10.1093/ajcn/34.9.1655

39. F. Shen, W. S. Cai, J. L. Li, Z. Feng and J. Cao, B. Xu, Biol. Trace Elem. Res., 167 (2015) 225.

https://doi.org/10.1007/s12011-015-0304-9
40. James J. DiNicolantonio, James H O'Keefe, and William Wilson, Open Heart, (2018) 5. https://doi.org/10.1136/openhrt-2017000668

41. J. Gorka, R. M. Taylor-Gjevre and T. Arnason, Int. J. Endocrinol., 2013 (2013) 638727.

https://doi.org/10.1155/2013/638727

42. K. N. Tu, J. D. Lie, C. K. V. Wan, M. Cameron, A. G. Aostel, J. K. Nguyen, K. Van and D. Hyun. P. T, 43 (2018) 92. https://www.ncbi.nlm.nih.gov/pubmed/2938 $\underline{6866}$

43. S. J. Chon, J. Y. Heo, B. H. Yun, Y. S. Jung and S. K. Seo, J. Menopausal Med., 22 (2016) 146.

https://doi.org/10.6118/jmm.2016.22.3.146

44. M. Gietka-Czernel, Prz Menopauzalny, 16 (2017) 33.

https://doi.org/10.5114/pm.2017.68588 